International Journal of Advanced Chemistry, 2(1) (2014) 6-11
International Journal of Advanced Chemistry
Journal home page: $\begin{gathered}\text { www.sciencepubco.com/index.php/IJAC } \\ \text { doi: } 10.14419 / \text { ijac.v2il.1620 } \\ \text { Research paper }\end{gathered}$

\title{
Investigation on polyaniline enriched tin cerium phosphate thermally stable fibrous composite ion exchanger for environmental remediation
}

\author{
Janardanan C*, Vinisha Valsaraj P \\ Research and Post Graduate Department of Chemistry, Sree Narayana College, Kannur, Kerala-670 007, India \\ *Corresponding author E-mail: jeeje_dianthus@yahoo.com
}

\begin{abstract}
Abstract: We fabricate a novel ion exchanger of tin cerium phosphate, by incorporation of polyaniline conducting polymer by ex-situ polymerization method, as a potential candidate for environmental remediation based on the concept of composite material. The study showed its utility as ion exchanger in the separation chemistry. SEM image of composite showed its fiber like morphology. The distribution coefficient studies showed its selectivity towards $\mathrm{Pb}$ (II) and $\mathrm{Bi}$ (III) metal ions. The adsorption isotherm and kinetic study of dye adsorption on this material was carried out. This study implies that this hybrid material can be suggested as eco-friendly material for the environmental monitoring.
\end{abstract}

Keywords: Adsorption, composite, ion exchanger, organic dye, polyaniline.

\section{Introduction}

Water pollution due to toxic metals and organic compounds remains a serious environmental and public problem. Heavy metal ions, aromatic compounds (including phenolic derivatives, and polycyclic aromatic compounds) and dyes are often found in the environment as a result of their wide industrial uses. They are common contaminants in wastewater and many of them are known to be toxic or carcinogenic. Therefore, removal of dyes from the wastewater has been an important environmental concern to minimize the water and soil pollution. Among the various method for the removal of dyes from wastewaters adsorption by ion exchanger is the most prominent and economic method.

Nowadays the studies of organic-inorganic composite materials got great attention in the field of ion exchanger due to their unusual properties by the combination of both organic and inorganic characteristics within a single molecular-scale. Composite exchangers have more advantages over organic and inorganic ionexchangers as they overcome two major drawbacks from which the latter suffers like thermal and chemical stability as well as reproducibility (Siddiqui et al. 2007). Inorganic ion exchanger based on organic polymeric matrix are interesting materials, as they possess mechanical stability due to the presence of organic polymeric species and the basic characteristics of an inorganic ion-exchanger regarding its selectivity for some specific metal ions. Due to these advantageous composite ion exchange materials have been extensively used in environmental remediation, analytical and electroanalytical processes such as waste water treatment, separation of metal ions, catalysis, polymer electrolyte membrane fuel cells and gas perm-selectivity (Niwas et al. 1999, Valaski et al. 2006, Yin X et al. 2006).

Recently, polyaniline (PANI) as an organic binder has been used to prepare new composites. The organic binder polymer is inert and the active component which possesses the ion-exchange property is inorganic ion-exchanger. Tin cerium phosphate is new member in the family of tetravalent based ion exchanger. By modifying its mechanical and ion-exchange properties, the new organic-inorganic composite, tin cerium phosphate-polyaniline ( $\mathrm{SnCeP}$ PANI) was synthesized and introduced in this paper.

The present paper is devoted to study the adsorption of the cationic dye methylene blue (MB) as a model dye into SnCeP-PANI composite. The principle is based on the chelating properties attributed to the electron-donating groups (amine and secondary amino groups) on the polyaniline polymers (Kong et al. 2011). Mahanta et al. (2008) used polyaniline emeraldine salt for the removal of sulfonated dyes. Ai et al. (2010) reported that the polyaniline microspheres possess potential efficiency to remove methyl orange from aqueous solutions. The difference between PANI nanofiber and the SnCeP-PANI composite toward the adsorption of MB was studied. The experimental variables affecting optimal adsorption were investigated. Various isotherm models and adsorption kinetics also was investigated in detail.

\section{Materials and methods}

\subsection{Reagents}

Stannic chloride (E.Merck), Ammonium Ceric Nitrate (E.Merck), Sodium dihydrogen phosphate (LobaChem) and aniline (E.Merck) were used for the synthesis of the exchangers. All other reagents and chemicals used were of analytical grade.

\subsection{Apparatus and instruments}

A glass column was used for column operations. ELICO LI613 $\mathrm{pH}$ meter was used for $\mathrm{pH}$ measurements. FT-IR Spectrometer 
model Thermo-Nicolet Avtar 370 for IR studies, X-ray Diffractometer Bruker AXS D8 Advance for X-ray diffraction studies, JEOL Model JSM - 6390LV for scanning electron microscopic analysis, TG Perkin Elmer Diamond TG/DTA Analysis System for thermogravimetric analysis were used. UV-Visible Spectrophotometer model JASCO V660 was used for spectrophotometric measurements.

\subsection{Synthesis of the exchanger}

\subsubsection{Synthesis of polyaniline}

Polyaniline gels were prepared by mixing of the acidic solutions of $10 \%$ aniline and $0.1 \mathrm{M}$ ammonium persulphate in different volume ratios with continuous stirring by a magnetic stirrer keeping the temperature below $10{ }^{\circ} \mathrm{C}$ for half an hour. Green colored polyaniline gels were obtained that were kept overnight in a refrigerator.

\subsubsection{Synthesis of tin cerium phosphate}

Ammonium ceric nitrate solution $(0.05 \mathrm{M})$, stannic chloride solution $(0.05 \mathrm{M})$ and sodium dihydrogen phosphate solution $(0.05 \mathrm{M})$ were prepared. Sodium dihydrogen phosphate solution was added to the mixtures of ammonium ceric nitrate solution and stannic chloride solution with constant stirring in different volume ratios so that final volume was $500 \mathrm{~mL}$. The yellow precipitates were obtained when the $\mathrm{pH}$ of the mixtures was adjusted to 1.0 by adding aqueous ammonia or hydrochloric acid with constant stirring. The excess reagents were removed by filtration.

\subsubsection{Preparation of tin cerium phosphate-polyaniline (SnCeP-PANI) composite cation exchanger}

The gels of polyaniline were added to the yellow inorganic precipitates of tin cerium phosphate and mixed thoroughly with constant stirring. The resultant green colored gels were kept for $24 \mathrm{hrs}$ at room temperature $\left(25 \pm 2{ }^{\circ} \mathrm{C}\right)$ for digestion. The supernatant liquid was decanted and gels were filtered under suction. The excess acid was removed by washing with deminerlized water (DMW) and the material was dried in an airoven at $50{ }^{\circ} \mathrm{C}$. The dried products were immersed in DMW to obtain small granules. They were converted to $\mathrm{H}^{+}$form by treating with $1.0 \mathrm{M} \mathrm{HNO}_{3}$ for $24 \mathrm{hrs}$ with occasional shaking, intermittently replacing the supernatant liquid with fresh acid. The excess acid was removed after several washings with DMW and the material was dried at $50{ }^{\circ} \mathrm{C}$. The particle of the size of the range $(\sim 125 \mu \mathrm{m})$ of the material was obtained by sieving and kept in desiccators for further studies. Hence, a number of samples of 'SnCeP-PANI' composite cation-exchanger were prepared and on the basis of $\mathrm{Na}^{+}$ion-exchange capacity, yield and physical appearance of beads one sample was selected for detailed studies.

\subsubsection{Ion exchange capacity (IEC)}

The ion exchange capacity of the material was determined by column method. The ion exchange capacity of the material was determined by column method. $1.0 \mathrm{~g}$ of the exchanger in $\mathrm{H}^{+}$form was taken in a glass column of $1.1 \mathrm{~cm}$ diameter. The $\mathrm{H}^{+}$ions were eluted by percolating $100 \mathrm{~mL}$ of $1.0 \mathrm{M} \mathrm{NaCl}$ solution. The effluent was collected and titrated against standard sodium hydroxide solution. The ion exchange capacity, IEC in meqg ${ }^{-1}$ was calculated using the formula,

$$
\text { IEC }=\frac{a v}{w}
$$

Where, $\boldsymbol{a}$ is the molarity, $\boldsymbol{v}$ is the volume of alkali used during titration and, $\boldsymbol{w}$ is the weight of the exchanger taken (Vogel 1975).

\subsubsection{Effect of temperature on IEC}

The effect of temperature on ion exchange capacity was studied by heating several $1.0 \mathrm{~g}$ samples of the exchanger at different tem- peratures for $2 \mathrm{hrs}$ in an air oven and $\mathrm{Na}^{+}$ion exchange capacity in meqg $^{-1}$ was determined by the column method after cooling them to room temperature.

\subsubsection{PH titrations}

Topp and Pepper method (Topp \& Pepper 1949) was used for $\mathrm{pH}$ titrations using $\mathrm{NaOH} / \mathrm{NaCl}, \mathrm{KOH} / \mathrm{KCl}$, systems. $0.5 \mathrm{~g}$ of exchanger was equilibrated with varying amounts of metal chloride and metal hydroxide solutions. At equilibrium (after equilibration), $\mathrm{pH}$ of the solutions was measured and plotted against the milliequivalents of $\mathrm{OH}^{-}$added.

\subsubsection{Distribution coefficient (KD)}

Distribution studies were carried out for various metal ions in demineralized water by batch process. In this method, $0.1 \mathrm{~g}$ of the exchanger (60-100 mesh) was equilibrated with $20 \mathrm{~mL}$ of the metal ion solutions for $24 \mathrm{hrs}$ at room temperature. The metal ion concentrations before and after sorption were determined spectrophotometically/ complexometric titration against standard EDTA solution. In the complexometric method, the $\mathrm{K}_{\mathrm{d}}$ values were calculated using the formula,

$K_{d}=\frac{(I-F)}{F} \times \frac{V}{W}$

Where, I is the initial volume of EDTA used, $\mathrm{F}$ is the final volume of EDTA used, $\mathrm{V}$ is the volume of the metal ion solution $(\mathrm{mL})$ and W is the weight of the exchanger (Vogel, 1975).

\subsubsection{Batch experiments for dye removal}

Batch experiments were performed according to Mahanta et al (2009). Briefly, $0.2 \mathrm{~g}$ of the SnCeP-PANI composite was agitated with $50 \mathrm{~mL}$ of dye solutions individually at $28{ }^{\circ} \mathrm{C}$ in a rotary incubated shaker for 2 hrs. The shaking speed was maintained at 180 $\mathrm{rpm}$ throughout the study. The dye solution was separated from the adsorbent by centrifugation at $6000 \mathrm{rpm}$. The dye concentration was analyzed by monitoring the absorbance of the dyes using UV-Visible Spectrophotometer (model JASCO V660). Experimental variables considered were (i) the effect of dosage of composite, (ii) initial dye concentration, (iii) effect of contact time and (iv) $\mathrm{pH}$ on the adsorption capacities.

\subsubsection{Desorption study}

The dye-loaded SnCeP-PANI composite, which were exposed to $20 \mathrm{mg} \mathrm{L}^{-1}$ of dyes at $28{ }^{\circ} \mathrm{C}$, was separated from the solution by centrifugation $(6000 \mathrm{rpm})$ and washed several times with water. Later, composite was dried completely and used for desorption experiments. The dye-loaded composites $(0.2 \mathrm{~g})$ were then brought into contact with $1.0 \mathrm{M} \mathrm{NaOH}, 1.0 \mathrm{M} \mathrm{HCl}, 1.0 \mathrm{M} \mathrm{HNO}_{3}$ ethanol (95\%), and acetone (99\%), separately. The mixture was agitated on a rotary shaker $(180 \mathrm{rpm})$ at $26{ }^{\circ} \mathrm{C}$ for $1 \mathrm{hr}$. After desorption, the supernatant was centrifuged, with the remaining procedure being the same as for the sorption experiments.

\subsubsection{Data analysis}

The percentage of removal of dyes was calculated using the following formula:

Removal $(\%)=\frac{C i-C e}{C i} \times 100$

Where, $\mathrm{Ci}$ is the initial dye concentration and $\mathrm{Ce}$ is the equilibrium dye concentration in $\mathrm{mg} \mathrm{L}^{-1}$. The maximum amount of dye adsorption at equilibrium was determined using the following equation:

$\mathrm{q}_{\mathrm{e}}=(\mathrm{Ci}-\mathrm{Ce}) \frac{V}{M}$

Where $\mathrm{Ci}$ and $\mathrm{Ce}$ is the initial and equilibrium dye concentration ( $\mathrm{mg} \mathrm{L}^{-1}$ ), $\mathrm{V}$ the solution volume, and $\mathrm{M}$ the mass of the composite used. The resulted equilibrium data were modeled using the 
Langmuir isotherm which can be expressed by the following equations (Langmuir 1916, Chowdhury \& Saha 2010):

Langmuir:

$$
\frac{C e}{q_{e}}=\frac{C e}{q_{m}}+\frac{1}{K_{L} q_{e}}
$$

Where $\mathrm{q}_{\mathrm{m}}$ is the maximum adsorption capacity $\left(\mathrm{mg} \mathrm{g}^{-1}\right), \mathrm{q}_{\mathrm{e}}$ the equilibrium adsorption capacity $\left(\mathrm{mg} \mathrm{g}^{-1}\right)$, Ce the equilibrium adsorbate concentration in solution $\left(\mathrm{mg} \mathrm{L}^{-1}\right)$, and $\mathrm{K}_{\mathrm{L}}$ is the Langmuir constant $\left(\mathrm{L} \mathrm{mg}^{-1}\right)$.

Adsorption kinetics was performed using both pseudo first- and second-order kinetics using the following equation (Ho \& McKay 1999, Ho 2004):

Pseudo first order:

$\log \left(\mathrm{q}_{\mathrm{e}}-\mathrm{q}_{\mathrm{t}}\right)=\log \left(\mathrm{q}_{\mathrm{e}}\right)-\left(\frac{k_{1}}{2.303}\right) t$

Pseudo second order:

$\frac{\mathrm{t}}{\mathrm{q}_{\mathrm{t}}}=\frac{1}{k_{2} q_{e}^{2}}+\left(\frac{1}{q_{e}}\right) \mathrm{t}$

Where $\mathrm{q}_{\mathrm{e}}$ is the amount of dye adsorbed at equilibrium $\left(\mathrm{mg} \mathrm{g}^{-1}\right), \mathrm{q}_{\mathrm{t}}$ the amount of dye adsorbed at time $\mathrm{t}\left(\mathrm{mg} \mathrm{g}^{-1}\right), \mathrm{k}_{1}\left(\mathrm{~min}^{-1}\right)$ is the pseudo first-order rate constant of the equation calculated from the slope of the plot $\log \left(\mathrm{q}_{\mathrm{e}}-\mathrm{q}_{\mathrm{t}}\right)$ vs. $\mathrm{t}, \mathrm{k}_{2}\left(\mathrm{~g} \mathrm{mg}^{-1} \mathrm{~min}^{-1}\right)$ is the pseudo second-order rate constant. A plot of $t / \mathrm{q}_{\mathrm{t}} \mathrm{vs}$. $\mathrm{t}$ yields a straight line with a slope of $1 / q_{e}$. The value of $k_{2}$ is determined from the intercept of the plot. Experiments were repeated for two times and mean values were considered. Blank experiments were carried out without adsorbents to ensure that the sorption of dye on the walls of flasks was negligible.

\section{Results and discussion}

A number of samples of 'organic-inorganic' composite cationexchanger tin cerium phosphate-polyaniline ( $\mathrm{SnCeP}-\mathrm{PANI}$ ) were prepared by mixing polyaniline into tin cerium phosphate in different mixing volume ratios. The composite material formed as black solid material (10\% polyaniline) has the ion exchange capacity of $1.28 \mathrm{meqg}^{-1}$ selected for further study. It was also noticed that the $\mathrm{Na}^{+}$ion-exchange capacity of the composite materials higher as compared to inorganic ion-exchanger tin cerium phosphate $\left(0.92 \mathrm{meqg}^{-1}\right)$.

In order to check the reproducibility of the prepared composite, it was synthesized four times under identical conditions of the concentration of reagents, mixing ratio and drying temperature. Ionexchange capacity and yield of each product were examined. The averages and standard deviation of the ion-exchange capacity and yield were found to be $1.28 \mathrm{meqg}^{-1}$ and $\pm 0.03 \%$, respectively.

Fig. 1 shows the FTIR spectrum of SnCeP-PANI. In the spectrum of the material, a strong and broad band around $3440 \mathrm{~cm}^{-1}$ is found which can be ascribed to $-\mathrm{OH}$ stretching frequency. A sharp peak around $1600 \mathrm{~cm}^{-1}$ can be attributed to $\mathrm{H}-\mathrm{O}-\mathrm{H}$ bending band, which represents the strongly bonded $-\mathrm{OH}$ groups in the matrix. A strong and broad band around $1000 \mathrm{~cm}^{-1}$ may represent the presence of ionic phosphate groups. An assembly of two sharp peaks in the region $500-800 \mathrm{~cm}^{-1}$ may be due to the presence of metal oxygen bond. Another assembly of two peaks in the region 1300$1400 \mathrm{~cm}^{-1}$ may be ascribed due to the stretching vibration frequency of $\mathrm{C}-\mathrm{N}$ in the material, as it also resembles the stretching vibration frequencies for C-N found in polyaniline (Rao 1963). This indicates that the tin cerium phosphate was modified with polyaniline.

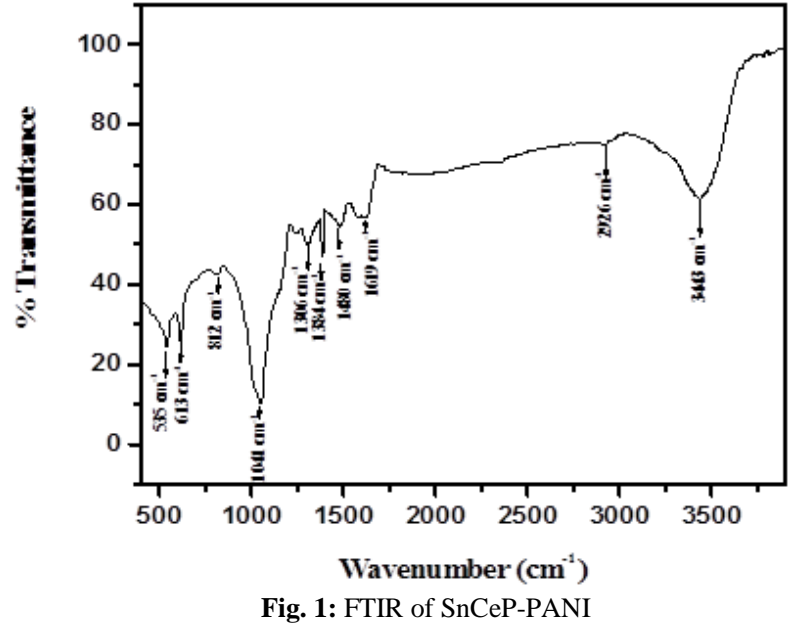

The TGA curve (Fig. 2) of both samples recorded continuous weight loss of mass up to $150{ }^{\circ} \mathrm{C}$, which may be due to the removal of external water molecule (Duval 1963). In the case of composite material there was a sudden weight loss at $550{ }^{\circ} \mathrm{C}$ it may be due to the decomposition of organic part. From $601{ }^{\circ} \mathrm{C}$ onwards, a smooth horizontal section represents the complete formation of the oxide form of the material.

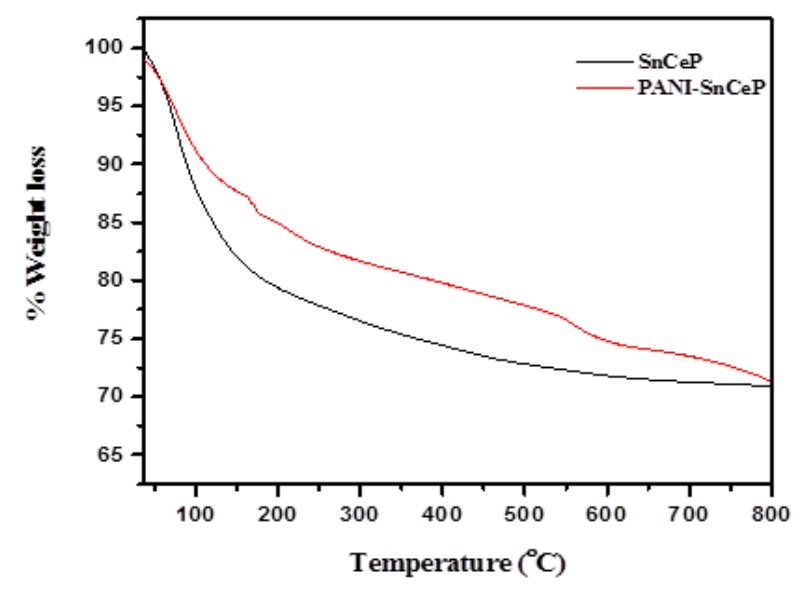

Fig. 2: TGA curves of SnCeP and SnCeP-PANI

X-ray diffractogram (Fig. 3) showed no prominent peaks which suggested amorphous nature of the composite material.

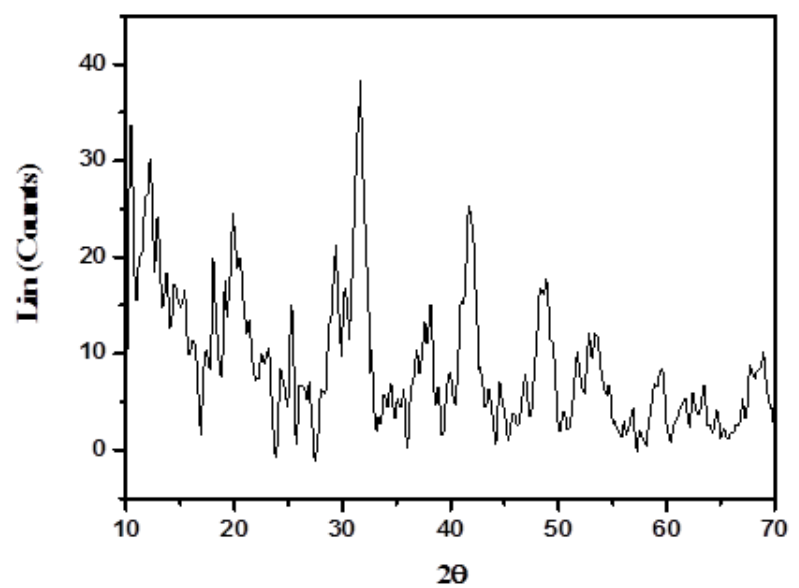

Fig. 3: XRD of SnCeP-PANI

The SEM images (Fig. 4) showed that the surface morphology of composite material is totally different from their individual inorganic components. The morphology of the composite material is essentially different due to the binding of polyaniline with tin 
cerium phosphate. The composite material indicated that its fiber like morphology.

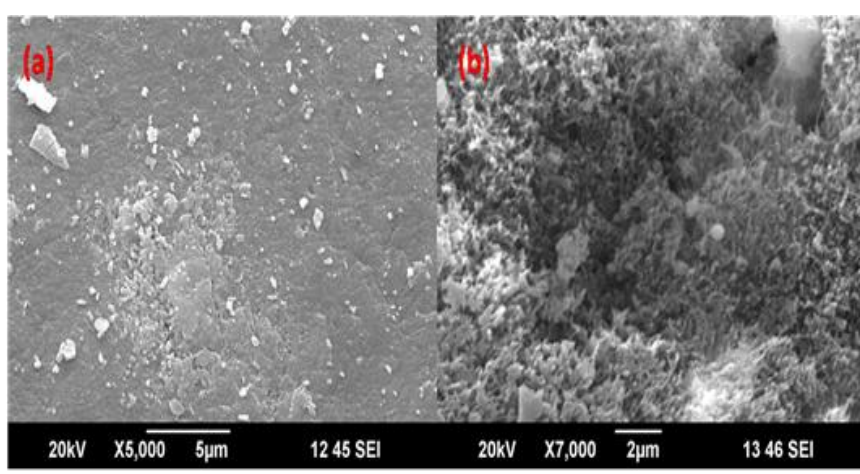

Fig. 4: (a) SEM image of SnCeP and (b) SEM image of SnCeP-PANI

$\mathrm{PH}$ titration curve obtained under equilibrium conditions for each of $\mathrm{NaOH} / \mathrm{NaCl}$ and $\mathrm{KOH} / \mathrm{KCl}$ system showed two inflection points which indicate the bifunctional behaviour of the material (Fig. 5). It appears to be a strong cation exchanger as indicated by a low $\mathrm{pH}(\sim 2.1)$ of the solution when no $\mathrm{OH}^{-}$ions were added to the system. The exchange capacity obtained from the curve is in agreement with that obtained by the column method.

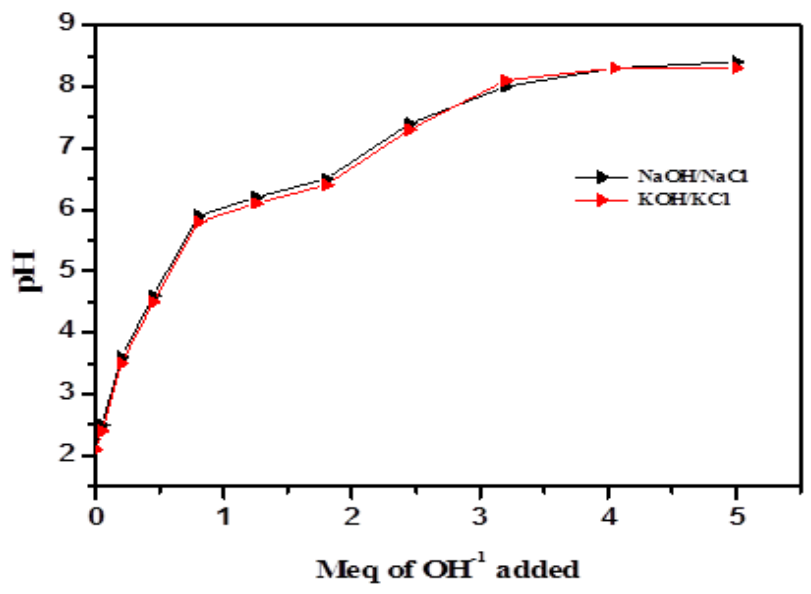

Fig. 5: pH titration curve of SnCeP-PANI

It was observed that on heating at different temperatures for $2 \mathrm{hrs,}$ the mass, and ion-exchange capacity of the exchanger were changed as the temperature increased (Fig. 6). The composite cation exchange material was found to possess good thermal stability as the sample maintained about $60 \%$ of the initial mass by heating up to $400{ }^{\circ} \mathrm{C}$. However, in respect to ion exchange capacity, this material was found to possess better thermal stability as the sample maintained $70 \%$ of the ion-exchange capacity up to $150{ }^{\circ} \mathrm{C}$ and it retained about $31 \%$ of the initial ion-exchange capacity by heating up to $300{ }^{\circ} \mathrm{C}$ and $11 \%$ up to $500{ }^{\circ} \mathrm{C}$ whereas tin cerium phosphate retained only $8 \%$ of ion exchange capacity up to $500{ }^{\circ} \mathrm{C}$.

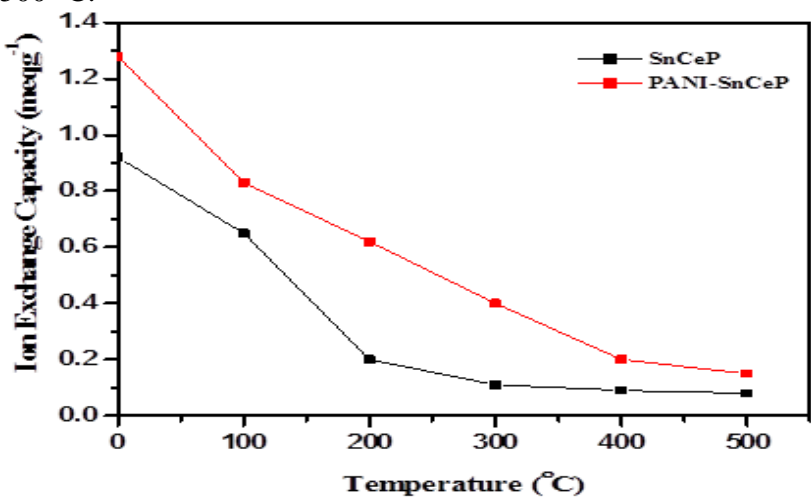

Fig. 6: Temperature effect on Ion exchange capacity of SnCeP and PANISnCeP

\subsection{Distribution studies}

In order to explore the potentiality of the new composite cation exchange material in the separation of metal ions, distribution studies for different metal ions were performed in different solvent systems shown in Table 1. The distribution studies of metal ions showed that the exchanger has very high affinity towards $\mathrm{Pb}$ (II) and $\mathrm{Bi}(\mathrm{III})$ ions in comparison to other metal ions studied. The selectivity was found to be in the order $\mathrm{Pb}$ (II) $>\mathrm{Bi}$ (III) $>\mathrm{Co}$ (II) $>$ $\mathrm{Cu}(\mathrm{II})>\mathrm{Zn}(\mathrm{II})>\mathrm{Ca}(\mathrm{II})>\mathrm{Mn}(\mathrm{II})>\mathrm{Ni}(\mathrm{II})>\mathrm{Hg}(\mathrm{II})>\mathrm{Mg}(\mathrm{II})$. The effect of electrolyte concentrations on distribution coefficients showed that the value decreases with increase in electrolyte concentrations.

Table 1: KD values of various metal ions in different electrolyte

\begin{tabular}{|c|c|c|c|c|c|c|c|}
\hline $\begin{array}{l}\text { Metal } \\
\text { ion }\end{array}$ & DMW & $\begin{array}{l}0.001 \mathrm{M} \\
\mathrm{HNO}_{3}\end{array}$ & $\begin{array}{l}0.01 \mathrm{M} \\
\mathrm{HNO}_{3}\end{array}$ & $\begin{array}{l}0.1 \mathrm{M} \\
\mathrm{HNO}_{3}\end{array}$ & $\begin{array}{l}0.001 \mathrm{M} \\
\mathrm{NH}_{4} \mathrm{NO}_{3}\end{array}$ & $\begin{array}{l}0.01 \mathrm{M} \\
\mathrm{NH}_{4} \mathrm{NO}_{3}\end{array}$ & $\begin{array}{l}0.1 \mathrm{M} \\
\mathrm{NH}_{4} \mathrm{NO}_{3}\end{array}$ \\
\hline $\mathrm{Pb}(\mathrm{II})$ & 300.00 & 256.00 & 200.00 & 166.00 & 288.00 & 201.00 & 156.00 \\
\hline $\mathrm{Zn}(\mathrm{II})$ & 40.00 & 25.00 & 12.12 & NA & 35.00 & 10.20 & NA \\
\hline $\mathrm{Mn}(\mathrm{II})$ & 27.00 & 11.90 & 2.32 & NA & 22.00 & 3.67 & NA \\
\hline $\mathrm{Ni}(\mathrm{II})$ & 17.00 & 1.12 & NA & NA & 15.00 & NA & NA \\
\hline $\mathrm{Hg}$ (II) & 14.00 & 2.19 & NA & NA & 10.00 & NA & NA \\
\hline $\mathrm{Ca}$ (II) & 38.00 & 29.00 & 19.00 & 9.00 & 34.00 & 25.00 & 12.00 \\
\hline $\mathrm{Cd}(\mathrm{II})$ & NA & NA & NA & NA & NA & NA & NA \\
\hline $\mathrm{Co}(\mathrm{II})$ & 75.75 & 64.12 & 34.00 & 19.01 & 70.12 & 59.00 & 29.12 \\
\hline $\mathrm{Cu}(\mathrm{II})$ & 72.00 & 56.99 & 23.70 & 14.55 & 70.01 & 59.90 & 24.50 \\
\hline Bi(III) & 185.00 & 177.12 & 134.22 & 100.00 & 182.34 & 123.90 & 99.90 \\
\hline $\operatorname{Mg}(\mathrm{II})$ & 8.50 & NA & NA & NA & NA & NA & NA \\
\hline
\end{tabular}

\subsection{Removal of dye}

Methylene blue (MB) was selected for this study. Adsorbent dosage is an important factor which must be carefully optimized during wastewater treatment. The effect of adsorbent dosage $(0.1-0.5$ g) on $20 \mathrm{mg} \mathrm{L}^{-1}$ concentration of MB dye solution was studied at $28{ }^{\circ} \mathrm{C}$ and neutral $\mathrm{pH}$ for $2 \mathrm{hrs}$, and the results are presented in Fig. 7(a). Initially, a rapid removal of dyes with the increasing adsorbent dosage was attributed to the availability of reactive sites (Almeida et al. 2009). A further increase in the composite dosage from $0.2 \mathrm{~g}$ to $0.5 \mathrm{~g}$ did not show much increase in the removal rate and adsorption equilibrium. Thus, further experiments were carried out using $0.2 \mathrm{~g}$ of the adsorbent, as it exhibits appreciable removal capacity for the optimization of adsorption parameters.

The adsorption of MB dye solution on composite at different initial concentrations $\left(20-100 \mathrm{mg} \mathrm{L}^{-1}\right)$ was analyzed for $2 \mathrm{hr}$ at $28^{\circ} \mathrm{C}$ and neutral $\mathrm{pH}$. The removal rate of the $\mathrm{MB}$ was varied according to the initial concentration of dye (Fig. 7(b)). At low concentration $\left(20 \mathrm{mg} \mathrm{L}^{-1}\right), 98.2 \%$ of dye was adsorbed by the composite. The enhanced removal at low concentration could be due to the faster movement of dye into the activated sites of composite. However, in higher concentration $\left(100 \mathrm{mg} \mathrm{L}^{-1}\right)$ the removal rate was decreased $(77.8 \%)$ because the dye molecules needed to diffuse to the adsorbent sites by intraparticle diffusion. In addition, steric repulsion between the solute molecules could slow down the adsorption process and there by decreases the removal rate. A similar trend was observed for the adsorption of methyl violet by agricultural waste (Hameed 2008).

MB solution $\left(50 \mathrm{~mL}, 20 \mathrm{mg} \mathrm{L}^{-1}\right)$ was treated with $0.2 \mathrm{~g}$ of exchanger for different periods of time (20-120 min) at $28^{\circ} \mathrm{C}$ and neutral $\mathrm{pH}$. The rapid removal was observed during the first 20 min and gradually decreased with laps of time until equilibrium. The increased activity at initial stage could be due to the availability of more adsorption sites on composite surface, and gradual occupancy of these sites reduced the reaction rate and the adsorption becomes less efficient. At this point, the amount of dye being adsorbed onto the composite was in a state of dynamic equilibrium with the amount of dye desorbed from the composite. The time required to attain this state of equilibrium was termed as equilibrium time, and the amount of dye adsorbed at the equilibrium time reflected the maximum adsorption capacity of the adsorbent under these particular conditions. It is evident from Fig. 7(c) that the 
contact time needed to attain the equilibrium condition for $\mathrm{MB}$ was about 2 hrs.

Several studies reported the significant role of $\mathrm{pH}$ in adsorption reaction. Crini et al. (2007) reported that the $\mathrm{pH}$ of the solution influences the surface charge and functional groups of the adsorbent. In addition, $\mathrm{pH}$ influences the degree of ionization of the materials present in the solution and solution chemistry. Hence, $0.2 \mathrm{~g}$ of the composite was mixed with $50 \mathrm{~mL}$ of dye solutions (20 $\mathrm{mg} \mathrm{L}^{-1}$ ) at different $\mathrm{pH}$ values (2-12) and kept for 2 hrs shaking. The $\mathrm{pH}$ was measured before the addition of the composite. From Fig. 7(d), it was observed that in basic $\mathrm{pH}$ composite adsorbs dye molecules, while in acidic $\mathrm{pH}$ the dye adsorption is comparatively low. The maximum adsorption of dyes (99.8\%) was observed at pH 12 and minimum adsorption (78.8\%) was observed at $\mathrm{pH} 2$. Lower adsorption percentage of MB on composite at highly acidic conditions is probably due to the presence of high concentration of $\mathrm{H}^{+}$ions on the surface of adsorbent competing with methylene blue (cationic dye) for adsorption sites in the adsorbent. With an increase in the solution $\mathrm{pH}$, the electrostatic repulsion between the positively charged methylene blue and the surface of adsorbent is lowered. Consequently removal efficiency is increased.
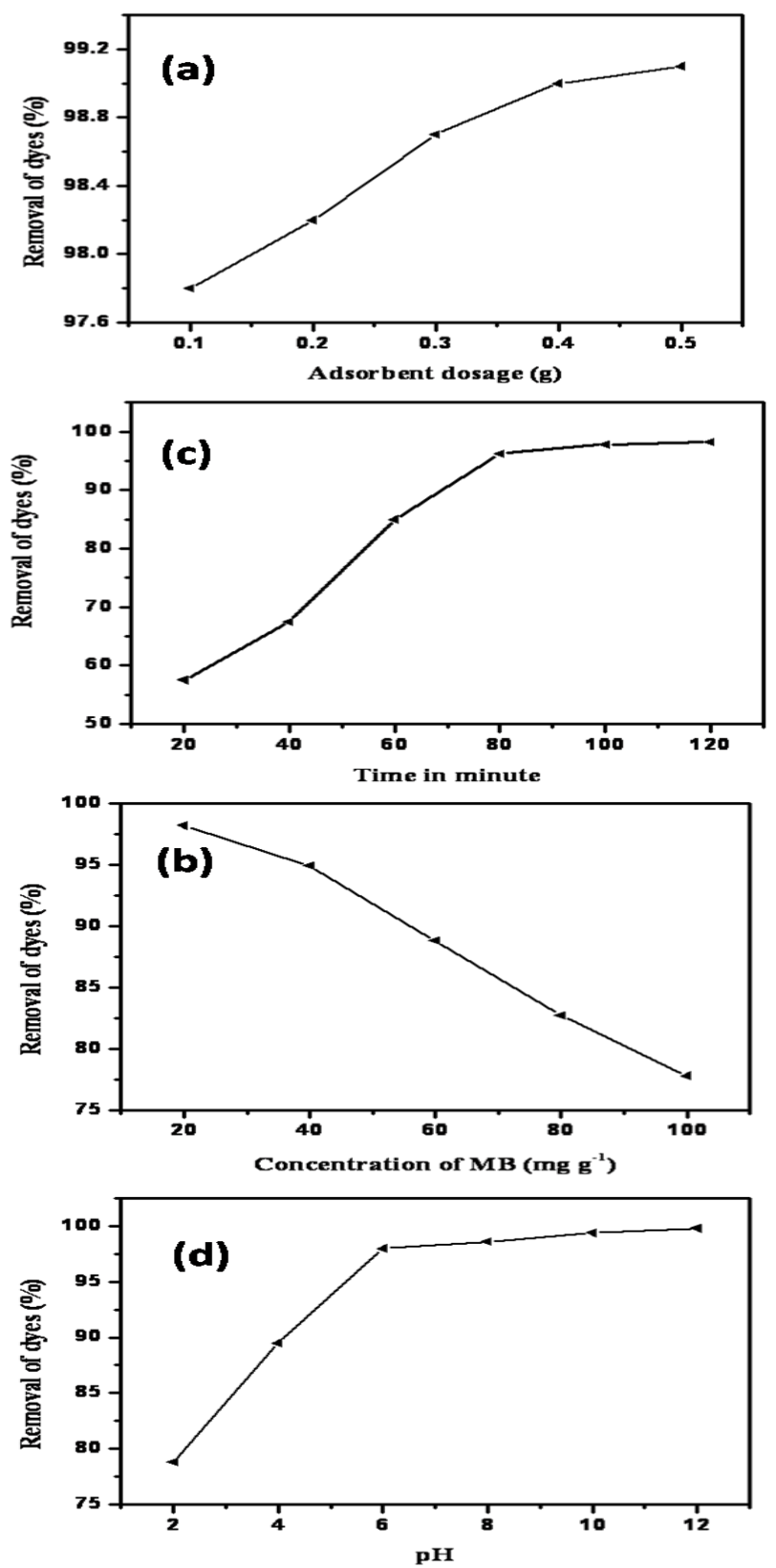

Fig. 7: (a) Effect of adsorbent dosage, (b) effect initial dye concentration, (c) effect of contact time and (d) effect of $\mathrm{pH}$ on the removal methylene blue by SnCeP-PANI.

\subsection{Equilibrium isotherms}

Adsorption equilibrium isotherm is one of the most important parameter required to understand the behavior of adsorption process. The shape of an isotherm gives the idea about the affinity of dye molecules and possible mechanism of adsorption. The adsorption isotherm study was carried out for $20 \mathrm{mg} \mathrm{L}^{-1}$ solution of MB at $28^{\circ} \mathrm{C}$ and neutral $\mathrm{pH}$ using $0.2 \mathrm{~g}$ of exchanger. In the present study, the experimental data were fitted to the Langmuir models. Langmuir isotherm has found successful applications in many other real sorption processes of monolayer adsorption. It depends on the assumption that intramolecular forces decrease rapidly with distance and consequently predicts the existence of monolayer coverage of adsorbate on adsorbent. The isotherm equation further represents that adsorption takes place at the specific homogenous sites within the adsorbent. A plot of Ce vs. (Ce/qe) resulted in a linear graphical relation indicating the application of the above model for MB (Fig. 8). The Langmuir model helps to estimate the maximum adsorption capacity $\left(\mathrm{q}_{\mathrm{m}}\right)$ when these could not be experimentally determined. The $\mathrm{q}_{\mathrm{m}}$ values observed for MB is 322.58 . The correlation coefficient constant $\mathrm{R}^{2}$ value of dye is approximately close to unity and which indicate that the adsorption reaction follows Langmuir isotherm model.

The amount of dye adsorbed, Qe ( $\mathrm{mg} \mathrm{g}^{-1}$ ) onto unit mass of SnCeP-PANI composite, PANI nanofiber, and $\mathrm{SnCeP}$ are equal to $5.38 \mathrm{mg} \mathrm{g}^{-1}, 4.48 \mathrm{mg} \mathrm{g}^{-1}$, and $0.61 \mathrm{mg} \mathrm{g}^{-1}$, respectively. Qe was calculated from the mass balance equation given by:

$Q e=(\mathrm{Co}-\mathrm{Ce}) \mathrm{Vm}^{-1}$

Where Co is the initial dye concentration in liquid phase, Ce is the liquid phase dye concentration at equilibrium, $\mathrm{V}$ is the volume of dye solution used, and $\mathrm{m}$ is the mass of adsorbent used. It is observed that adsorbed amount of MB increases in the following series: SnCeP-PANI composite > PANI nanofiber $>$ SnCeP. The binding sites of the interactions available in the SnCeP-PANI composite would be larger due to synergetic effect of inorganic counterpart and polyaniline along with the fiber like morphology; hence, more intensive interaction with the cationic dye MB occurs.

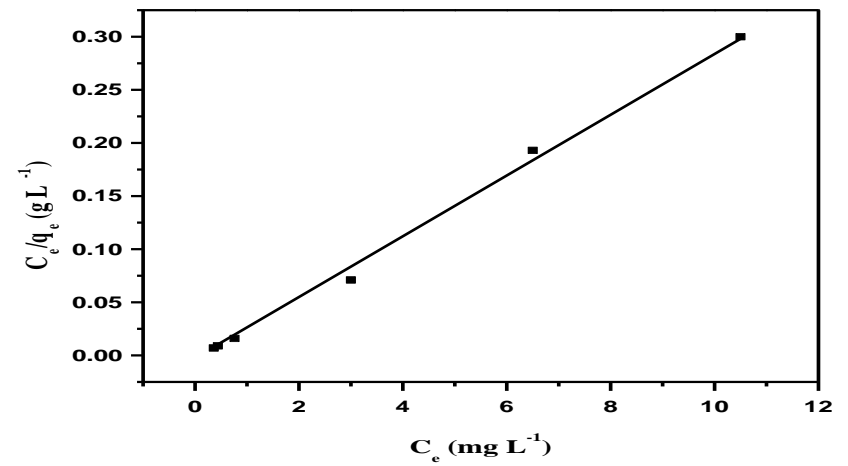

Fig. 8: Langmuir isotherms for the adsorption of MB on SnCeP-PANI composite.

\subsection{Adsorption kinetics}

The kinetic study of the adsorption processes often used to describe the efficiency of adsorption and feasibility of scale-up operation. Kinetics of adsorption equilibrium is also needed to evaluate the effectiveness of the adsorbate (Dogan et al. 2009). For the kinetic study $20 \mathrm{mgL}^{-1}$ concentration of dye solution was treated with $0.2 \mathrm{~g}$ of exchanger. Pseudo first-order and second-order kinetic models were used to gain a better understanding of the adsorption processes. First, the kinetic data were fitted to the pseudo first-order kinetic model. The validity of the model is checked by the regression coefficient $\left(\mathrm{R}^{2}\right)$, and the equilibrium sorption capacities appeared that the pseudo first-order model was not fit well with the experimental data. Hence, the kinetic data were further modeled with the pseudo second-order kinetic equation. The applicability of the pseudo second-order kinetic model for MB dye 
was examined by the linear plots of (t/qt) vs. t (Fig. 9). The adsorption correlation coefficient $\mathrm{R}^{2}$ was approximately close to unity, which fits the experimental data better than the pseudo firstorder for the entire adsorption process. The kinetics of the adsorption followed pseudo second-order rate expression, which demonstrates that intraparticle diffusion plays a significant role in the adsorption mechanism. In other words, the adsorption of MB favorably follows pseudo second-order model, and the rate of the reaction appeared to be controlled by the chemical process.

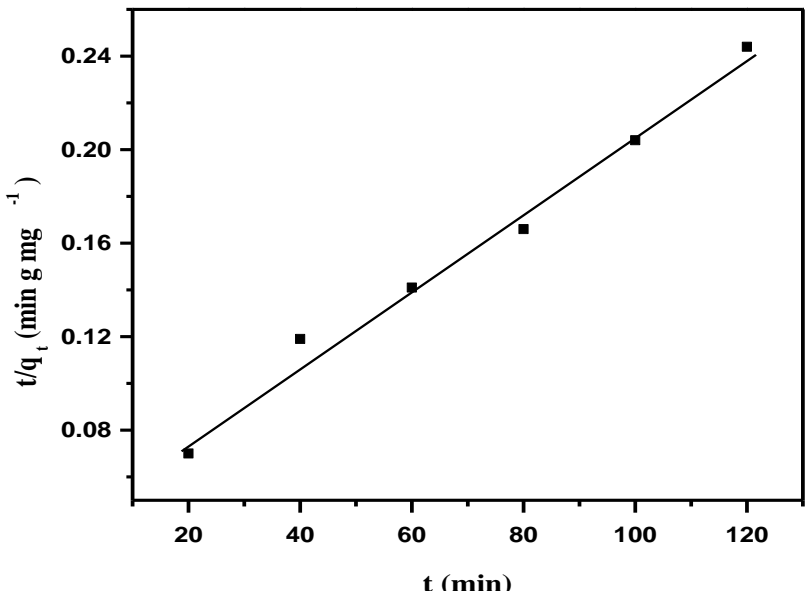

Fig. 9: Pseudo second-order kinetics plots for MB on SnCeP-PANI composite.

\subsection{Desorption study}

After confirming the fact that SnCeP-PANI is capable of adsorbing the dye molecules onto its surface, it becomes necessary to know the process by which the dye molecules remain adhered to the surface of the composite. The adherence of dye molecules onto the surface of the composite was purely chemical interactions, involving chemical binding of the substances. The chemical bonding can be elicited by subjecting the adhered material to desorption and regeneration process (Adamson 1960). In this study, desorption experiments were conducted using $1.0 \mathrm{M} \mathrm{NaOH}, 1.0 \mathrm{M}$ $\mathrm{HCl}, 1.0 \mathrm{M} \mathrm{HNO}_{3}$, ethanol, and acetone to ascertain the nature of binding of dye molecules onto the composite surface. Treatment with $\mathrm{HNO}_{3}(1.0 \mathrm{M})$ shows the considerable recovery of the dyes $(84 \%)$. Under acidic condition, the positively charged sites increase onto the composite surface, and it acts as a driving force for the elution of dye by electrostatic repulsion. However, negligible recovery of dyes was observed after treatment with $1.0 \mathrm{M} \mathrm{NaOH}$. In the series of five sorption and desorption cycle, the loss in the sorption capacity was less than $7 \%$. Hence, composite can be easily regenerated and reused for the practical purposes.

\section{Conclusion}

The synthesized thermally stable fibrous tin cerium phosphatepolyaniline cation exchanger is a novel ion-exchange material. The fibrous like morphology and the synergetic effect of tin cerium phosphate and polyaniline, helps this material as potential candidate for the removal of MB. The equilibrium data have been analyzed using Langmuir isotherm model and represented the equilibrium adsorption data. Kinetic studies point to the fact that the adsorption dynamics of dye is predicted more accurately by the pseudo-second order model. Thus, this new composite is promising for environmental applications in wastewater treatment in textile or other industries dealing with heavy metal ions as well as dyes.

\section{Acknowledgement}

Author gratefully acknowledges the Council of Scientific and Industrial Research (CSIR), New Delhi, for the award senior research fellowship. The author is also gratefully acknowledged to STIC, Cochin for instrumental support.

\section{References}

[1] Adamson AW (1960) Physical Chemistry of Surface, Interscience Publishers, Inc., New York.

[2] Ai L, Jiang J \& Zhang R (2010) Uniform polyaniline microspheres: A novel adsorbent for dye removal from aqueous solution, Synthetic Metals. 160(7-8):762-767.

[3] Almeida CAP, Debacher NA, Downs AJ, Cottet L \& Mello CAD (2009) Removal of methylene blue from colored effluents by adsorption on montmorillonite clay, Journal of Colloids and Interface Science 332(1):46-53.

[4] Chowdhury S \& Saha P (2010) Sea shell powder as a new adsorbent to remove Basic Green 4 (Malachite Green) from aqueous solutions: Equilibrium, kinetic and thermodynamic studies, Chemical Engineering Journal 164(1):168-177.

[5] Crini G, Peindy HN, Gimbert F \& Robert C (2007) Removal of C.I. Basic Green 4 (Malachite Green) from aqueous solutions by adsorption using cyclodextrin-based adsorbent: Kinetic and equilibrium studies, Separation and Purification Technology 53(1):97-110.

[6] Dogan M, Karaoglub MH \& Alkan M (2009) Adsorption kinetics of maxilon yellow 4GL and maxilon red GRL dyes on kaolinite, Journal of Hazardous Materials 165(1-3):1142-1151.

[7] Duval C (1963) Inorganic Thermogravimetric Analysis, Elsevier, Amsterdam, 315.

[8] Hameed BH (2008) Equilibrium and kinetic studies of methyl violet sorption by agricultural waste, Journal Hazardous Materials 154(13):204-212.

[9] Ho YS (2004) Citation review of Lagergren kinetic rate equation on adsorption reactions, Scientometrics. 59(1):171-177.

[10]Ho YS \& McKay G (1999) Pseudo-second order model for sorption processes, Process Biochemistry. 34:451-465.

[11]Kong Y, Wei J, Wang Z, Sun T, Yao C \& Chen Z (2011) Heavy metals removal from solution by polyaniline/palygorskite composite, Journal of Applied Polymer Science 122(3):2054-2059.

[12]Langmuir I (1916) the constitution and fundamental properties of solids and liquids. Part i. Solids, Journal of American Chemical Society 38(11):2221-2295.

[13] Mahanta D, Madras G, Radhakrishnan S \& Patil S (2008) Adsorption of Sulfonated Dyes by Polyaniline Emeraldine Salt and Its Kinetics, Journal of Physical Chemistry B 112:10153-10157.

[14]Mahanta D, Madras G, Radhakrishnan S \& Patil S (2009) Adsorption and desorption kinetics of anionic dyes on doped polyaniline, Journal of Physical Chemistry B 113:2293-2299.

[15]Niwas R, Khan AA \& Varshney KG (1999) Synthesis and ion exchange behaviour of polyaniline $\quad \mathrm{Sn}(\mathrm{IV})$ arsenophosphate: a polymeric inorganic ion exchanger, Colloid. Surf. A. 150(1- 3):7-14.

[16]Rao CNR (1963) Chemical Applications of Infrared Spectroscopy, Academic Press, New York, 250.

[17] Siddiqui WA, Khan SA \& Innamuddin (2007) Synthesis, characterization and ion-exchange properties of a new and novel 'organicinorganic' hybrid cation-exchanger: Poly(methyl methacrylate) Zr(IV) phosphate, Colloid. Surf. A. 295:193-199.

[18]Topp NE \& Pepper KW (1949) Properties of ion-exchange resins in relation to their structure. Part I. Titration curves, Journal of Chemical Society 690:3299-3303.

[19] Valaski R, Muchenski F, Mello RMQ, Micaroni L, Roman SS \& Hummelgen IA (2006) Sulfonated polyaniline/poly (3methylthiophene)-based photovoltaic devices, Journal of Solid State Electrochemistry 10(1):24-27.

[20] Vogel AI, "A text book of quantitative inorganic analysis", Longman Group Limited, London, 1975.

[21] Yin X, Ding J, Zhang S \& Kong J (2006) Enantioselective sensing of chiral amino acids by potentiometric sensors based on optical active polyaniline films, Biosensers Bioelectronics 21(11):2184-2187. 